\title{
Incidence of Malignancy in Asymmetrical Tonsillar Enlargement
}

\author{
Jalal Al Marzooq, Jawad Abdulla, Mahmood Al Sindi \\ Department of Otorhinolaryngology (ORL), Salmaniya Medical Complex, Manama, Bahrain \\ Email:jalmarzooq@yahoo.com
}

How to cite this paper: Al Marzooq, J., Abdulla, J. and Al Sindi, M. (2017) Incidence of Malignancy in Asymmetrical Tonsillar Enlargement. International Journal of Otolaryngology and Head \& Neck Surgery, 6, 6-10.

http://dx.doi.org/10.4236/ijohns.2017.61002

Received: November 10, 2016

Accepted: January 17, 2017

Published: January 20, 2017

Copyright $\odot 2017$ by authors and Scientific Research Publishing Inc. This work is licensed under the Creative Commons Attribution International License (CC BY 4.0).

http://creativecommons.org/licenses/by/4.0/

\begin{abstract}
Objective: To determine the incidence of carcinoma in patients with asymmetrical tonsillar enlargement. Study Design: A clinical retrospective case series based on medical records of our medical complex. Results: During a two-year period, 990 patients underwent tonsillectomy at Salmaniya Medical Complex (SMC). 59 (5.9\%) of those patients had asymmetrical enlargement of their tonsils, three of whom had suspicious clinical findings at presentation. The latter were found to have tonsillar malignancy on histopathological testing. Malignancy was excluded in all other specimen. Conclusions: Since the incidence of malignancy in asymmetrical tonsils is negligible in the absence of other associated risk factors, watchful waiting may be appropriate prior to any surgical intervention. Diagnostic tonsillectomy is indicated in patients with asymmetrical tonsillar enlargement with associated suspicious clinical findings, including cervical lymphadenopathy and rapid tonsillar enlargement.
\end{abstract}

\section{Keywords}

Tonsil, Asymmetry, Enlargement, Malignancy, Tonsillectomy

\section{Introduction}

Tonsils are lymphoid tissue collections located at either side of the oropharynx. They are primarily made of B lymphocytes and are lined by stratified squamous epithelium. They lack afferent lymphatic channels. Their main function is to production antibodies, lymphokines and gamma interferon. There are several etiologies behind unilateral tonsillar enlargement, including tuberculosis, actinomycoses, syphilis and sarcoidosis [1], chronic inflammatory response, papilloma [2], reactive immunological response to a nearby primary tumor in cervical lymph node and malignancy. Furthermore, asymmetric tonsils could be a normal variant due to varying depth of tonsillar fossa or asymmetry in anterior pillars.

Tonsillectomy is among the most commonly performed operations in otorhi- 
nolaryngology (ORL). The indications are classified into absolute and relative indications. Malignant tumors of the tonsil are one of the definitive indications for tonsillectomy. Suspected tonsillar malignancy cannot be confirmed except after biopsy is done, usually tonsillectomy.

Tonsillar malignancy has different presentations. It could present as ulcerated tonsillar mucosa as in squamous cell carcinoma of the tonsil. However, a normal tonsillar mucosa does not exclude tonsillar malignancy. For example, nonepidermoid malignancy of the tonsil can present with asymmetrical tonsillar enlargement with normal mucosa. The aim of this study is to determine the incidence of malignancy in patients with asymmetrical tonsillar enlargement.

\section{Patients and Methods}

Patients who underwent tonsillectomy in the period of January 2002 until December 2003 were included in the study. We conducted a clinical retrospective review of our institution's experience with unilateral tonsillar enlargement in the mentioned period. All of the preoperative clinical findings were reviewed. The size of each tonsil was documented in patient's medical records using a clinical assessment scale (CAS) of $0,+1,+2,+3,+4$. This scale evaluates tonsillar hypertrophy relative to the midline $(0=$ absent, $1+=$ small within the tonsillar fossa, $2+$ extends beyond the tonsillar pillar, $3+=$ enlarged tonsils but not touching the midline, $4+=$ enlarged tonsils touching the midline). Asymmetric tonsils included all tonsils with different CAS between the right and left sides. The patient's age, gender, tonsil size, associated symptoms, suspicious findings and pathology results were entered for all patients. Tonsil size was measured in histopathology laboratory postoperatively, the three-dimensional volume being calculated. Ethical clearance to review the medical records of our patients was approved by the Ministry of Health, Salmaniya Medical Complex, Bahrain. There were no missing data or data outliers for our subjects. Limitations for our study included small sample size and ethnicity; since all the patients were Bahraini, our findings may not translate to patients of other ethnicities.

Data were recorded and analyzed using SPSS version 20 software.

\section{Results}

During the two-year period, 990 patients underwent tonsillectomy at SMC. 59 (5.9\%) of those patients had asymmetrical enlargement of their tonsils. Of the 59 patients, 33 were male and 26 were female patients (Table 1). Ten (16.9\%) out of

Table 1. Gender distribution of patients with tonsil asymmetry.

\begin{tabular}{ccccc}
\hline \multicolumn{5}{c}{ Tonsillar size (CAS) } \\
\hline & Frequency & Percent & Valid percent & Cumulative percent \\
\hline+1 & 20 & 33.9 & 33.9 & 33.9 \\
+2 & 27 & 45.8 & 45.8 & 79.7 \\
+3 & 12 & 20.3 & 20.3 & 100.0 \\
Total & 59 & 100.0 & 100.0 & \\
\hline
\end{tabular}


the 59 patients did not have a diagnosis of asymmetry on histopathological testing as compared to the CAS. All the patients had CAS difference between tonsils. 20 patients had a difference of $1+, 27$ patients had a difference of $2+$ and 12 patients had a difference of $3+$ between the CAS for each tonsil (Table 2).

Three (5\%) of the 59 patients had benign lesions on their unilaterally-enlarged tonsil (Table 3 and Figure 1). Two patients had paillomatous hyperplasia of the squamous epithelium on histopathology and were diagnosed with papilloma. The third patient was diagnosed with neurofibroma of the tonsil on histopathological examination. All of them had suspicious clinical findings on examination, including papillomatous lesions over the tonsil and greyish tonsillar discoloration, respectively. In addition, $3(5 \%)$ of the 59 patients were found to have malignant changes of their tonsils (Table 3 and Figure 1). All of those patients had preoperative signs raising the possibility of malignancy. The first patient was a 44 year-old Bahraini male, found to have ulcer over his left unilaterally-enlarged tonsil. Histopathology testing showed that the tonsil was completely replaced by diffuse lymphoid infiltrate composed of sheets of pleomorphic large cells with nucleoli and occasional tangible body macrophages. He was diagnosed with large cell diffuse B cell lymphoma. The second patient was a 65 year-old Bahraini male who also had ulcerative lesions over both tonsils associated with cervical lymphadenopathy. On histopathological examination, the tonsil showed loss of follicular architecture with monotonous sheets of lymphoid cells, oval nuclei and prominent nucleoli. Mitotis figures and foci of necrosis were noted. Immunohistochemistry was strongly positive for B cells (CD 20). He was diagnosed with B-cell type low-grade non-Hodgkin lymphoma. The third patient was a 60 year-old Bahraini female who had palpable cervical lymphadenopathy. She had subepithelial infiltration of her tonsil by clumps and sheets of large neoplastic cells composed of vesicular nuclei, multiple nucleoli and considerable pleomorphism with occasional mitotic figures. She was diagnosed with invasive poorly-differentiated nonkeratinizing squamous cell carcinoma.

Table 2. Tonsil size difference (CAS).

\begin{tabular}{ccccc}
\hline \multicolumn{5}{c}{ Gender } \\
\hline & Frequency & Percent & Valid percent & Cumulative percent \\
\hline Male & 33 & 55.9 & 55.9 & 55.9 \\
Female & 26 & 44.1 & 44.1 & 100.0 \\
Total & 59 & 100.0 & 100.0 & \\
\hline
\end{tabular}

Table 3. Histopathology of asymmetrically-enlarged tonsils.

\begin{tabular}{ccccc}
\hline \multicolumn{5}{c}{ Histopathology } \\
\hline & Frequency & Percent & Valid percent & Cumulative percent \\
\hline Lymphoid hyperplasia & 53 & 89.8 & 89.8 & 89.8 \\
Malignant tumor & 3 & 5.1 & 5.1 & 94.9 \\
Benign tumor & 3 & 5.1 & 5.1 & 100.0 \\
Total & 59 & 100.0 & 100.0 & \\
\hline
\end{tabular}




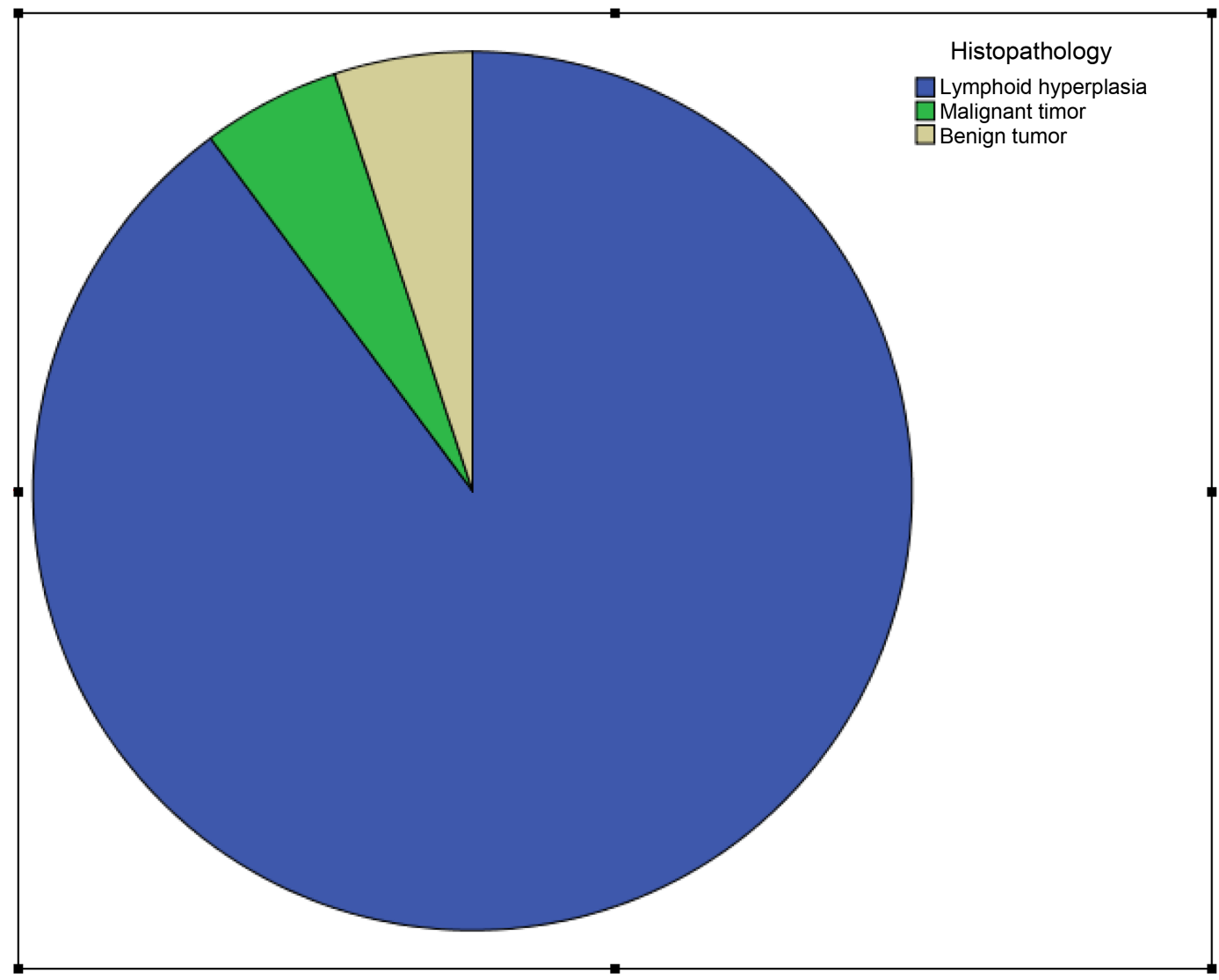

Figure 1. Distribution of subjects according to histopathology.

\section{Discussion}

According to the American Academy of Otolaryngology-Head and Neck Surgery Clinical Indicator Compendium [3], unilateral hypertrophy of the tonsil presumed to be neoplastic is an indication for tonsillectomy. Otolaryngologists have to weigh the risks and complications of doing tonsillectomy versus the possibility of missing a diagnosis of malignancy. In patients with unilateral tonsillar hypertrophy associated with other signs pointing towards malignancy, the possibility of cancerous changes is high and tonsillectomy is usually done. However, patients who have normal physical examination findings including absent ulceration of the tonsils, absent cervical lymphadenopathy and other systemic symptoms, the decision whether to do tonsillectomy or not becomes more challenging.

In a similar study [4], 70 patients underwent tonsillectomy to rule out malignancy in asymmetrically-enlarged tonsils. Histopathology was unremarkable except in one, B-cell lymphoma. This patient did not have cervical lymphadenopathy or other associated systemic symptoms.

Another study [5] included 49 patients whose only indications for tonsillectomy was asymmetrical enlargement. Only 2 of the patients were diagnosed with cancerous changes. According to the study, there is no alternative modality to tonsillectomy in such patients; for instance, "the sensitivities and specificities for fine-needle aspiration in the tonsil have not been reported". Overall, the results of our study as well as similar studies could be interpreted to mean that a significant 
Table 4. Tonsil size on histopathology testing versus tonsil size on CAS.

\begin{tabular}{ccccccc}
\hline & \multicolumn{5}{c}{ Tonsillar size on histopathology } \\
\cline { 3 - 6 } & & 0 & +1 & +2 & +3 \\
\cline { 2 - 6 } & & Count & Count & Count & Count \\
\hline \multirow{2}{*}{ Tonsillar size on examination (CAS) } & +1 & 10 & 10 & 0 & 0 \\
& +2 & 0 & 7 & 20 & 0 \\
& +3 & 0 & 0 & 6 & 6 \\
\hline
\end{tabular}

percentage of patients have undergone a "needless" surgery. But up till now, tonsillectomy is still necessary and is the only definitive way to confirm tonsillar malignancy.

Furthermore, $10(16.9 \%)$ of the patients did not have actual asymmetry after the pathology test results were known (Table 4). CAS is the clinical evaluation of the hypertrophy of the tonsils in relation to the midline. This means that the physician could notice asymmetry of the tonsils while being of the same size.

\section{Conclusion}

Since the incidence of malignancy in asymmetrical tonsils is negligible in the absence of other associated risk factors, watchful waiting may be appropriate prior to any surgical intervention. Diagnostic tonsillectomy is indicated in patients with asymmetrical tonsillar enlargement with associated suspicious clinical findings, including cervical lymphadenopathy and rapid tonsillar enlargement. Imaging modalities could be helpful in assessing the asymmetry of the tonsils when suspecting such finding on clinical examination.

\section{References}

[1] Compadretti, G.C., Nannini, R. and Tasca, I. (2003) Isolated Tonsillar Sarcoidosis Manifested as Asymmetric Palatine Tonsils. American Journal of Otolaryngology, 24, 187-190. https://doi.org/10.1016/S0196-0709(03)00006-1

[2] Spinou, C., Kubba, H., Konstantinidis, I. and Johnston, A. (2005) Role of Tonsillectomy in Histology for Adults with Unilateral Tonsillar Enlargement. British Journal of Oral and Maxillofacial Surgery, 43, 144-147. https://doi.org/10.1016/j.bjoms.2004.01.009

[3] (1999) Clinical Indicators Compendium. Washington, DC: American Academy of Otolaryngology-Head and Neck Surgery. 17.

[4] Najeeb, T. and Chattah, R.U. (2013) Frequency of Malignancy in Asymptomatic Unilateral Enlarged Tonsil. Journal of Rawalpindi Medical College (JRMC), 17, 262 264.

[5] Syms, M.J., Birkmire-Peters, D.P. and Holtel, M.R. (2000) Incidence of Carcinoma in Incidental Tonsil Asymmetry. The Laryngoscope, 10, 1807-1810. 
Submit or recommend next manuscript to SCIRP and we will provide best service for you:

Accepting pre-submission inquiries through Email, Facebook, LinkedIn, Twitter, etc. A wide selection of journals (inclusive of 9 subjects, more than 200 journals)

Providing 24-hour high-quality service

User-friendly online submission system

Fair and swift peer-review system

Efficient typesetting and proofreading procedure

Display of the result of downloads and visits, as well as the number of cited articles Maximum dissemination of your research work

Submit your manuscript at: http://papersubmission.scirp.org/

Or contact ijohns@scirp.org 